\title{
Innovation Analysis on Tourism English Teaching Practice Approach in Tibet
}

\author{
Rui Deng
}

School of Foreign Language, Tibet University for Nationalities, Xianyang, 712082,China

\author{
Keywords: Tourism English of Tibet. Tibet Tourism. Teaching Simulation. Practice
}

\begin{abstract}
In order to implement the tourism English teaching in universities of Tibet with more flexibility and utility, this paper has placed the innovation analysis on the teaching and practice approaches. On one hand, according to the characteristic culture of Tibetan Culture, to develop the corresponding methods of translation is one of the workable approaches; on the other hand, based on business of tourism, to develop the specific English copywriting design and composition is another effective approach.
\end{abstract}

\section{Introduction}

With the development of Tibet Tourism, the requirements of professional persons who know Tibetan culture very well and communicate and advertise Tibet with English fluently as well are rising in sharply. However, the professionals who meet the requirements are in great shortage, which is disjointed with the local tourism market requirements. This has limited the tourism of Tibet marching forward to globalization. The responsibility of a lecturer in university of Tibet is to think and develop the innovated teaching and practice of tourism English, focusing on the development of Tibet, tourism of Tibet, the tourism English teaching practice in local university and the vocational development of Tibet students. Therefore, the university can provide the society with talents that satisfy the requirements of local tourism market.

\section{The Function of Tourism English in Development of National and Tibetan Area Tourism}

With the globalization of Chinese tourism, the tourism English has played a very significant role. The tourism English has built up the bridge between the scenic regions and internationality, especially for those famous and well-built scenic regions over the world. For Tibet, a new coming but well-known scenic region, it must make use of tourism English to achieve its globalization, according to the successful experience of other famous examples nationwide. The tourism English has not only built up the bridge of globalization, demonstrated local and ethic special culture, but also create a path to receive the suggestions from local tourists and tourists from other countries to mitigate the weak points or flaws of our nationality. It is both the advertisement of local culture and the enhancement of local tourism.

\section{The Present Teaching Situation of Tourism English in Universities of Tibet}

According to contemporary tourism English teaching and learning in universities of Tibet, it still continues to use the traditional teaching method, which is exam-oriented teaching, while students are learning to pass the exam. Hence, this kind of teaching approach has led to the graduates with insufficient vocational abilities.

The teaching content can't demonstrate the ability practice but overly concern with the graduation of students

For nowadays teaching and learning mode of tourism English majors, the content has still adapted to the culture, history, relevant scenic spots and tourism commences of English-speaking countries. Additionally, the evaluation of students in learning is still the ordinary written examination, containing listening sometimes. This kind of evaluation is lack of relevant examination on practice, 
which is apart from the future career development of the tourism situation and the development of students. However, the tourism English is one of the application languages, providing services for tourism. Tourism English can be fractionized as advertisement of products, the communication of tourism customization, the introduction of the scenic spots and relevant cultures, the planning of activities with in scenic spots and corresponding copywriting of practical writing. The subdivision is divided according to the occasions where requires the tourism English, such as travel agency, hotels, scenic spots and various media, depending on the development of local tourism. Therefore, the tourism English teaching in universities of Tibet can't satisfy the requirements of

\section{Single approach on teaching for lecturers and lack of practice for students}

Attribute to the limitation of evaluation system, tourism English teaching in universities of Tibet keeps in the classrooms that students listen to the lectures, halting at the background of high school students to perform practice about listening, reading, speaking, writing and translation. But, the curriculum placement is lack of special practice concentration on tourism. Meanwhile, the silent English has become the universal phenomenon of students in English, who are not able, not dare, not willing to speak English, so that they can neither speak good English, nor fluently communicate with others in English. The universities have already noticed the problems, and have equipped some advanced teaching facilities. However, the facilities are just the assistant in teaching, which is not the inspiration to stimulate students' learning interest. Under some other situations, the universities have provided a student-oriented platform, while their study is separated from tourism; without the interconnection between tourism and scenic spots, the tourism English has been apart from development of students vocation and tourism. For this approach, students are equipped with broaden horizon indeed; however, this horizon has been limited in the classroom, and not triggered the motivation in advanced learning of students.

\section{Ignoring the Specification of Tibet culture and lack of practice on translation}

The culture of Tibet, as a specific and precious culture heritage, has been developed and enriched continuingly, after over 4,000 years' development. Therefore, the English teaching in universities of Tibet, the content must focus on the history, culture and local specialty of Tibet and perform the teaching with local characteristics. Firstly, the translation of specific Tibetan cultural nouns must be pay enough attention to, which means the globalization of the pronunciation, sound mark, meaning, the characteristic of these nouns, to make them become the nouns in common use accepted internationally. Secondly, minimize the difference in translation of Tibetan language and culture into English, which means the precise demonstration of Tibetan specialty with comprehensive, particular and accurate translation. Thirdly, seize the main stream. For example, perform tourism English teaching with focus on the main stream as local religious, national and festival culture, so that the English teaching will have practical meaning.

\section{Innovation on Tourism English Teaching and Practice Approaches of Tibet}

As a significant part of Chinese tourism, tourism in Tibet has become the desire of both domestic and international tourists for its special value in tourism. To cope with the rapid development of transportation and hardware situation, the professionals in tourism, especially the ones with foreign language must meet the desire of market, so that they can improve the development of economics in Tibet, via the development of local tourism. Therefore, the tourism English teaching of local students must have oriented to the market, the tourists, and the popularization of local folk, religion and relevant culture. The basis for this must is generated from the innovation of lectures.

\section{Hands-on Instruction and practice under Coalition of College and Enterprise Periodically}

The teaching of tourism English requires on-site situational teaching at the relevant places periodically, according to the requirements of teaching content. On one hand, it is to run a joint school with relevant scenic spots, periodically shifting some area of the scenic spots as the teaching area. For example, when it comes to the Shoton Festival of Tibetan tradition, the Drepung Monastery could be the joint school area. Students are required to tell the history of the festival and the scenic spots, the culture value of Tibetan people that behind this festival to the tourists. This kind of teaching requires 
the students coming to the site, mobilizing themselves and then touching the tourists based on their love on Tibet. On the other hand, invite the staff in relevant occupations to prepare speech in the classroom, introducing their own actual work experience and explaining how to provide satisfactory service to foreign tourists. In one word, this approach is to introduce the requirements and development trend of the market into the classroom according to the desire of Tibet tourism, letting students feel both pressure and motivation. However, there are three points to be considered for this approach. Firstly, don't make the class simply becoming visiting or playing. The whole teaching process must under the supervising of lecturer, who has controlled the progress of the class, and set the order of practice, such as in group, one by one or in turn. Second, the time control must be kept in the lecturer's mind. Time should be kept in proper, if too short, the students must lack of practice on site. Third, make full use of students assisted instruction. It is recommended to divide the students into groups, let them discuss, judge, peer-review and evaluate of each other. They can find out the problems of each other. When the dispute occurs the teacher would be the arbitration.

\section{Enhance on-site simulation teaching and practice of nodes of tourism via multimedia}

This approach is to ask the professionals in relevant occupations, or lecturers teaching the students in English, setting the real working environment from the screen of multimedia. For example, provide the corresponding topics with scenarios and ask the students having conversations in English. The topics generally come from the real situations came across by the worked people. Meanwhile, the lecturer could play the role of foreign tourists, asking students the questions about Tibet culture. After the students gave the answers, lecturers would provide their answers for the students to refer to. This simulation teaching approach will definitely increase the understanding of this job of the students, triggering their interest on study; meanwhile, the approach will satisfy the desire of practical training required by this course, so that the students could hold the post of guide in English professionally. The simulation teaching approach will consolidate their background for their future career.

\section{Enhance the creation of tourism commentaries, and enhance the teaching of reading and translation}

The primary issue exited in tourism English is the poor practical English of the students. In general, the application ability of English is much poorer than their understanding of local culture. To find out the root for this phenomenon, on one hand, it is the poor or lack of self-motivation of creation of these students. On the other hand, the particularity of Tibet culture is lack of sufficient research, so that there is not corresponding acceptance or advertisement over the world. In view of this situation, the main purpose of teaching must inspire the motivation of students, to transfer the listening, reading, speaking, writing and translation from our textbook to the pre-arranged planning of scenic spots in practice among Tibet tourism, and the creation of commentary, etc. Therefore, the concentration of our teaching approach must experience a shift according to the development of tourism in Tibet. This shift should firstly start from the reorganization of teaching content. For example, require the students to adapt the information of domestic and international scenic spots and to change it into the commentary that suitable for local scenic spots. Definitely students impossibly provide a satisfactory commentary in the beginning, due to the limitation of vocabulary, the skill of writing, the grammar or the understanding of idioms. Therefore, teachers should follow up the problems that may have happen, to pilot the students the adaption from origins step-by-step. Meanwhile, teachers should help students to tell the different requirements of corresponding application writing, such as the advertisement layout and the commentary of scenic spots. Secondly, reinforce the translation practice on Tibetan history and culture. For example, under the instruction of teacher, according to the levels, perform translation practices on the topics of nation history, the religions, the nation culture, the nation etiquette and the festival traditions of Tibet. Particularly, must pay special attention on translation of some specific nouns, avoiding any offence on the taboos. Thirdly, try to create their commentaries in English by themselves for the well-known Tibet scenic spots. Especially for those scenic spots and historic sites well-known domestically and internationally of Tibet, such as the Potala Palace, Jokhang Temple, Drepung Monastery, Ruins of Guge Dynasty, Norbulingka Summer Palace, etc., teacher would ask the students to write down their English commentaries according to 
their opinions. It is not only the improvement on their writing skills, but also the exercise of their practical abilities.

\section{Simulation of orientation teaching}

The tourism English is one of the application English categories, which need to be considered about the directions of vocation. It is with few possibilities to educate graduates with strong professional skills merely over the campus. Therefore, the education must connect closely with market, with the development of tourism and the contribution of the tourism teams. The orientation teaching connected to enterprises must be reinforced, to facilitate the education direction over campus with the desire of market. There are two approaches to perform the innovated education, according to present practice and the requirements of market. On one hand, send the students to practice in the scenic spots of Tibet. This approach requires the teacher to make appropriate arrangement according to the learning abilities of students. For example, the students with poor spoken English will be arranged to the receptions, such as the hotels for international tourists, motor corporations, restaurants and scenic spots to enhance their practice in English. The purpose of this approach is to motivate the learning desire of students in the practical environment, and to exercise their skills corresponding with their weak points. On the other hand, the approach is simply to introduce. It is to transfer the nodes of tourism into teaching scenarios and bring them into campus and classrooms, so that teacher could design the content of teaching according to the scenarios and provide the lectures with intention. For one instance, prepare a project which requires the students to create a mini travel agency, assisting them run well with the allocation work of a travel agency. For another instance, prepare some special topic conversation about some festivals, to improve the simulated application of tourism English under this circumstance. In one word, the foundation of this approach is to build up real workplace to perform the practical teaching and learning, helping students transfer from textbook learning into practice in future career.

\section{Conclusion}

As the springboard for the careers of graduates, the tourism English teaching must consider about the development of market and tourism. Particularly for tourism English of students in Tibet, the teaching must focus on the tourism development in Tibet and perform education with intention, based on the successful experience from local peers. On one hand, tourism English teaching must enhance the education on future occupational planning of students, so that the students will twist the English learning and application with their future career life positively, with motivation, pressure and strength. On the other hand, to reinforce the education marching with the tourism, it is not to concentrate on the examinations but their application ability. For example, the students major in tourism English should spend their energy on the certificate of foreign language tour guide, and how could they become a competent guide for international tourists in Tibet, or how could they become an appropriate guide to lead local tourists travelling abroad. All these practices are basically original from the teaching over campus, combined with fruitful practical teaching, so that the knowledge learned from textbook will transfer to practical abilities.

\section{References}

[1] Yu Luo, Research and Practice on tourism English practical education of higher vocational colleges with "ERP Sand Board plus tour guide placement", Journal of Changchun University (Natural Science Edition), 2011, 21(5)

[2] Zhumei Lin, Research on Reorganization of tourism English Teaching Approaches in Higher Education, Journal of Langfang Normal College (Social and Science Edition), 2011,27(4)

[3] Zhiguo Tang, Research on Education of International and Practical Graduates in Tourism English of Higher Vocational Colleges, Shandong Normal University (Natural Science Edition), 2011, 26 (4) 
[4] Hong Yu, Innovation and Practice of New built Practical Teaching System for English Majors (Tourism) in Universities, Education of Heilongjiang, Research and Evaluation of Higher Education, 2011, (12)

[5] Xiangling Geng, Research on Internalization and Negative and External Effects in Development of Tourism in Tibet, Journal of University of Tibet (Social Science Edition), 2012, 27(1)

[6] Hui Li, Ga-Zang-Cai-Dan, Tu-Deng-Ke-Zhu, Construction of Training System of Internal Service personnel in Tibet Scenic Spots, Journal of University of Tibet (Social Science Edition), 2011, 26(3) 